\title{
Combining BIM and Last Planner on construction sites: an investigation of the related challenges
}

\author{
Yaya Pitti ${ }^{\mathrm{a}}$, Conrad Boton ${ }^{\mathrm{a}, *}$, Daniel Forgues ${ }^{\mathrm{a}}$ \\ ${ }^{a}$ École de Technologie Supérieure, 1100, rue Notre-Dame Ouest, Montréal, Canada
}

\begin{abstract}
The construction industry is facing a gradual but important transformation towards more productivity and collaboration. In this framework, two major approaches are often cited in the literature as having the potential to improve the practices in the industry: Building Information Modeling (BIM) and Lean Construction. Several scientific studies have demonstrated the synergy of these two approaches and very recent research has reported positive results from the use of software applications as support for their implementation on construction sites. However, the stakes of such integration have been very little studied. This article presents the results of a research project conducted within a general contractor firm that decided to implement BIM and Last Planner System (LPS) on its construction sites. The research uses a four-stage action research approach, including the characterization of the research issue, the establishment of an action plan, its implementation and its evaluation.

Compared to recent related studies, the research is less enthusiastic. While it highlights the need for new tools to improve production planning and control, it also points to a strong resistance to change by practitioners at the site. They emphasize the necessity for adequate pre-service training and the need for new resources that can work full-time on the ongoing training of site teams. In addition, some limitations of the tool lead workers to believe that it can quickly become a factor that slows down their daily work rather than improving it.
\end{abstract}

(C) 2019 The Authors. Published by Budapest University of Technology and Economics \& Diamond Congress Ltd.

Peer-review under responsibility of the scientific committee of the Creative Construction Conference 2019.

Keywords: Building Information Modeling; Last Planner System; Construction site.

\section{Introduction}

The construction industry is generally considered to be an underperforming industry, compared to other manufacturing industries such as aerospace and automotive [1,2]. This lack of performance is reflected in particular by low productivity and frequent overruns of costs and delays [3-5]. Yet, in recent years, the growing adoption of new technological approaches seems to have the potential to change the game [6]. Among these approaches, Building Information Modeling (BIM) occupies an important place [7]. The early years of the BIM approach focused on the development of technological solutions, for example to solve important issues such as interoperability. But rather quickly, it became clear that the added value of such an approach should reside, not only in the arrival of new technologies, but also and above all in improving the dynamics of collaboration, the integration of the supply chain and the elimination of waste. In this context, several research projects have highlighted the necessary complementarity between BIM and Lean approaches $[8,9]$. The synergy between the two approaches has been 
Yaya Pitti. et al. / Proceedings of the Creative Construction Conference (2019) 113

https://doi.org/10.3311/CCC2019-113

widely discussed in the literature and the added value of such a combination has been demonstrated [10-13]. But very little work has been devoted to the issues related to the combined use of these two approaches, which, even if they are recognized as complementary, each require a particular methodology and important means to implement.

This article presents the results of a research project conducted with a general contractor firm that decided to implement BIM and Last Planner System (LPS) on its construction sites. It aims at exploring the main challenges to overcome in order to successfully implement LSP-BIM software. The rest of the article is organized in four main sections. The first section presents a literature review whose purpose is to define the main concepts to understand the problem, and to present the state of the art on the question. The second section presents the research methodology. The third part presents the main results, which are discussed next in the fourth section.

\section{Related works}

\subsection{Definitions and main concepts}

The success of Lean principles and the perceived benefits of using it in the manufacturing industry have prompted construction stakeholders to adopt these principles [14]. According to Koskela et al. [15], Lean Construction is a way of studying the production system by minimizing waste of materials, time and effort in order to generate maximum added value. Among the various Lean Construction techniques, LPS is one of the most popular methods of production planning and control [16]. The LPS was developed to improve the performance of construction projects by increasing the reliability of schedules and workflow [17]. It is also used to reduce variability and uncertainty in construction [18]. According to Ballard and Howell [19] the planning process of the Last Planner system is a procedure for creating a Master Schedule, a Reversed Phase Scheduling, a Lookahead Schedule, and a Weekly Work Plan, using Lean Construction planning techniques.

Building Information Modeling (BIM) consists in the use of "a multidisciplinary object-oriented 3D model of the constructed facility to improve and to document its design and to simulate different aspects of its construction or its operation" [20]. Thus, it focuses on the development, the use and the transfer of digital information models of a construction project to improve its design, construction and operation [21]. BIM becomes essential for the realization of construction projects and its deployment offers both benefits and challenges in its implementation [22]. It is increasingly required in the execution of projects and for many clients it becomes a requirement to be fulfilled for the grant of the project. Its importance and effectiveness have been proven through several projects [7]. Additional information can be added to the three-dimensional model(s) for analyses and simulation purposes. In this context, it is commonly agreed that $4 \mathrm{D}$ models are created by linking scheduling information to the $3 \mathrm{D}$ model in order to simulate the process of construction over time [23]. 5D BIM models are prepared for cost management purposes [24]. It is more and more accepted that the sixth and the seventh dimensions are related to energy analysis and assets management purposes, but it is important to note that beyond the fifth dimension (i.e. cost), there is no consensus in the literature about what each dimension represents.

\subsection{BIM and LPS association in the literature}

In 2010, Sacks et al. [11] conducted an analysis of the interactions between BIM and Lean approaches. They noticed that "a synergy exists which, if properly understood in theoretical terms, can be exploited to improve construction processes beyond the degree to which it might be improved by application of either of these paradigms independently". They then proposed a juxtaposition of the Lean Construction principles and the BIM functionalities, and factually identified 56 interactions [11]. In 2014, Khan and Tzortzopoulos [25] proposed a discussion on how the association of BIM and LPS can affect the design workflow. The discussion, based on two building design projects, used the interaction matrix developed by Sacks et al. [11] and showed that such an association "can improve workflow in building projects through features that reduce waste". Indeed, as demonstrated by Seppänen et al. [26], to be fully successful, the BIM adoption needs to be associated with a lean managerial approach like LPS to control.

Otherwise, the implementation "can lead to inefficiencies even when the technological approach is effective" [25]. 
Yaya Pitti. et al. / Proceedings of the Creative Construction Conference (2019) 113

https://doi.org/10.3311/CCC2019-113

The case study presented by Clemente and Cachadinha [13] identified a number of contributions of BIM to the materialization of the principles of Lean, based on the fact that the BIM methodology has parallel principles with most of the Lean Construction principles. According to Clemente and Cachadinha [13], the BIM model can add a needed visual dimension to the project. This visual dimension can be aligned to all the information available and the BIM features can be exported, so "the works were easily controlled and the facility management improved. This also enabled the implementation of a LPS planning approach for daily activities planning" [13]. However, some limitations and constraints have been identified, including the initial cost, the know-how and the fact that BIM is a time-consuming approach.

More and more commercial software are being proposed, aiming at combining BIM and Lean principles, using mobile technologies. These tools include BIM 360 Plan, LeanKit, VisiLean, TouchPlan, etc. BIM 360 Plan is a collaborative 'Look Ahead Planning' tool. The master schedule can come from traditional planning tools (MS Project or Primavera). Leankit uses a virtual Kanban board, to enable the creation of a master schedule with the participation of the whole construction team, but does not offer visualization of the 3D model. VisiLean is a production management system specifically designed for planning and production control. It supports the Last Planner system workflow, including detailed constraint analysis and assignment of resources to tasks. The master schedule and the 3D model are imported into the software. It allows simultaneous visualization of the Gantt and the 3D model for 4D simulation purposes. TouchPlan uses a virtual table integrated in the software, to enable the creation of a master schedule. It is also possible to import a master schedule from traditional planning software such as MS Project or Primavera. However, it does not display the 3D model. Very few research works [29-31] have been dedicated to the evaluation of Lean-BIM software, especially from the perspective of the practitioners.

\section{Research approach}

Action research is considered as a research method that requires contact with the field and the reality. The purpose of this approach is to identify needs or problems, before establishing a strategy to achieve change objectives in response to observed problems [32]. The action research follows the four main steps: the characterization of the research issue, the establishment of an action plan, its implementation and its evaluation.

The analysis of existing processes used by the industrial partner highlighted some gaps to cover by the implementation of a new technological tool that combines LPS and BIM. To understand the context and the needs, an analysis of the planning and production practices as well as interviews with the involved actors (Project Manager, Superintendent, Planner, and Assistant Project Manager) was necessary. The action plan established as part of this research consists of the following steps: Choosing a solution, defining a scenario, choosing a pilot project, implementing the solution and gathering feedback from project stakeholders. The choice of the solution is made based on selection criteria coming from a synthesis of the literature, including the BIM features, LPS features, collaboration and interoperability features, usability, and accessibility. The scenario adopted consists of a preliminary step of training the participants and organizing an indoor simulation on the operation and use of the software, and to define with the participants an action plan for the use of the solution on the construction site. A pilot project was selected to test the software, relating to the construction of a sports centre and whose structure consists of steel and reinforced concrete elements. The project is realized in turnkey and Fast Track modes. The practitioners' feedbacks were collected through semi-directive interviews.

\section{Main results}

\subsection{Choosing new tools to improve production planning and control}

The industrial partner is facing problems related to the limitations of traditional methods of planning and controlling production. The current planning method is traditional (Push Planning) and its practice generates the difficulties such as the delay in the delivery of the works, the waste, and a decrease in productivity. The master schedule is designed in general without much contribution from the specialized contractors. The visualization of the schedule in BIM 4D is not yet adopted by the industrial partner. Certainly, there are important advances in terms of information sharing 
Yaya Pitti. et al. / Proceedings of the Creative Construction Conference (2019) 113

https://doi.org/10.3311/CCC2019-113

through the Procore project management platform, since all the reports and the drawings are accessible through this platform. The need for new tools integrating BIM and LPS comes from the desire of the industrial partner to improve it production planning and control. But such integration should not be limited to software tools alone, but should take into account the need to update current processes, in order to create a propitious context for the successful implementation of the software on construction sites.

Following the analysis of the planning software integrating LPS and BIM, and according to the identified selection criteria, the two selected software are BIM 360 Plan and VisiLean. Admittedly, the two programs are similar and make it possible to perform collaborative planning and production control with different approaches. However, BIM 360 Plan looks a lot more at collaborative planning while VisiLean has an additional function which offers a visualization of the elements of the project through the 3D model. It has been decided to test and to evaluate BIM 360 Plan for production planning and VisiLean for production control. In this logic, the planning process is divided into three phases: preliminary planning, planning integrating the LPS, and the use of the BIM 360 Plan. The preliminary planning is done in collaboration with the construction team and the planner. They use the drawings and the 3D model to generate a preliminary schedule. The schedule integrating the LPS is done in collaboration with the construction team, the planner and all the specialized contractors. They refer to the preliminary schedule, the 3D drawings and models to produce a schedule according to the LPS approach. The use of BIM 360 Plan converts the schedule defined according to the LPS approach into 'Milestone Breakdown Structure', and proposes an electronic version of the detailed schedule, and the lookahead Schedule. The 'Weekly Work Plan' and the 'Daily Work Plan / Coordination' are generated by the software. The construction team must ensure that all specialized contractors have access to the software so that they can plan to perform the tasks to which they are committed.

Regarding the production control using VisiLean, a working process has also been proposed. Before starting the execution of the tasks, the specialized contractors must carry out a constraint analysis 'Constraint Removal', this allows them to make the task ready to be executed (Task Make Ready). The software calculates the weekly Percent Plan Complete (PPC) for each specialized contractor. The construction team having access to the software can consult the progress of the work of each specialized contractor, and ensure by a physical verification in the field if the work is compliant or does not comply. The PPC produced by each specialized contractor, in addition to physical verification, can help the validation of the payment request of the specialized contractors. The Project Control Manager also has access to the software. This allows him not only to monitor the progress of the work of the specialized contractors, but also to know the overall progress of the work of the general contractor (by consulting the PPC to date). An instant notification system informs all project stakeholders of changes. The control manager and the management team are informed daily of the status of the project. The verification and the validation of the payment requests of the specialized contractors and the general contractor are made easy. For this preliminary case study on issues related to the implementation, we limited the research to the specialized contractors and the general contractor.

\subsection{The main challenges}

The study showed a contradiction of point of view between the top management and the site team. The top management manifests the need to innovate and supports the idea of implementing the software. For the top management, such an implementation can be useful not only to optimize the planning process, but also to enable a variety of new usages. For example, using the software can help in "exploring the capability to leverage the PPC report data to facilitate the payment of subcontractors", said the project director at an introductory meeting. Moreover, the top management was keen to reduce delays when performing the site work. "Can an alert be triggered when an activity is late compared to its due date?" asked the project director. However, the construction team has an opinion contrary to that of top management. It finds that the adoption of this software means an additional constraint. The construction team finds it difficult, if not impossible, to get the cooperation of all the specialized contractors as the assistant project manager testifies: "It will be impossible to use in the field because all the employees are busy and specialized contractors will not be able to collaborate". "Superintendents and representatives of subcontractors will have a hard time accepting to use it because the software increases the volume of work", he adds. Throughout the participant interviews, participants expressed doubt about the operation and effectiveness of this new software. 
Yaya Pitti. et al. / Proceedings of the Creative Construction Conference (2019) 113

https://doi.org/10.3311/CCC2019-113

The site team showed strong opposition to the implementation of the tool. For $70 \%$ of participants, the hesitation and the doubt are justified by the lack of knowledge and experience on the software. For 30\% of participants, reluctance to adopt a new, little-known approach creates resistance to change. They find that it is risky to rely entirely on technology. "When the system does not work after an internet interruption or technical failure, it delays our work and we are wasting time", the superintendent stated.

The lack of knowledge is frequently mentioned in interviews. Eight out of ten participants (80\%) do not know the LPS, however the 10 respondents say they know BIM. This lack of knowledge is justified by the fact that the LPS is a new concept for many construction companies. However, encouraging feedbacks have been received from the planner: "We would like to adopt the LPS if it is an approach that will simplify our planning", he says. For a successful adoption of the LPS, it is important to train the workers and to show them the added value of this approach. The need for training was raised by each of the interview participants. It is important to set up a continuing education program for software users, in both LPS and BIM. The testimonials gathered are of the same opinion as that of the project manager. "I think that we must train workers to hope to successfully implement the software combining LPS and BIM, and require its use in contractual clauses", he says. The Superintendent draws on his past experience with implementing BIM to emphasize the importance of worker training. "BIM is a very good tool, but workers do not know how to use it", he concludes.

Throughout the interviews, participants expressed doubt about the operation and effectiveness of this new software. For 70\% of participants (seven out of 10), hesitation and doubt are justified by the lack of knowledge and experience on the software. For $30 \%$ of participants (three out of ten), reluctance to adopt a new, and little-known approach creates resistance to change. They find that it is risky to rely entirely on TM, as the Superintendent testifies, "When the system does not work after an internet interruption or technical failure, it delays our work and we are wasting time. Having a full-time person in the field for technical assistance and ongoing training of software users can simplify the software adoption, and can motivate and encourage workers to use the software well. The superintendent's testimony supports the need to have a champion assigned to the project "This is a good opportunity, but it will be difficult to implement if a resource responsible for the tool is not recruited to conduct the implementation ". The project manager is of the same opinion. "Not having a person dedicated to the management of the documentation makes the work of the project manager quite painful when searching for documents. [...] We must also recruit a person in full time who will take care of the daily training of users and the use of LPS and BIM software throughout the project", he says.

\section{Conclusion and future work}

The research presented in this paper aims at exploring the main challenges to overcome in order to successfully implement LSP-BIM software. It highlights the need for new tools to improve production planning and control, but also points to a strong resistance to change by practitioners at the site. They emphasize the necessity for adequate pre-service training and the need for new resources that can work full-time on the ongoing training of site teams. In addition, some limitations of the tool lead workers to believe that it can quickly become a factor that slows down their daily work rather than improving it. Future works will focus on how to optimize the continuum of information between design team and the construction site, in order to fully benefit from the capabilities offered by BIM models.

\section{References}

[1] C. Boton, L. Rivest, D. Forgues, J. Jupp, Comparing PLM and BIM from the product structure standpoint, 2016. doi:10.1007/978-3-31954660-5_40.

[2] B.J. Gledson, D. Greenwood, The adoption of 4D BIM in the UK construction industry: an innovation diffusion approach, Engineering, Construction and Architectural Management. 24 (2017) 950-967. doi:10.1108/ECAM-03-2016-0066.

[3] Y.M. Cheng, An exploration into cost-influencing factors on construction projects, International Journal of Project Management. 32 (2014) 850-860. doi:10.1016/j.ijproman.2013.10.003.

[4] H. Doloi, Cost Overruns and Failure in Project Management: Understanding the Roles of Key Stakeholders in Construction Projects, Journal of Construction Engineering and Management. 139 (2012) 267-279. doi:10.1061/(ASCE)CO.1943-7862. 
Yaya Pitti. et al. / Proceedings of the Creative Construction Conference (2019) 113

https://doi.org/10.3311/CCC2019-113

[5] I. Abdul Rahman, A. Hameed Memon, A. Tarmizi Abd Karim, Significant Factors Causing Cost Overruns in Large Construction Projects in Malaysia, Journal of Applied Sciences. 13 (2013) 286-293. doi:10.3923ljas.2013.286.293.

[6] A. O. AlSehaimi, P. Tzortzopoulos Fazenda, L. Koskela, Improving construction management practice with the Last Planner System: a case study, Engineering, Construction and Architectural Management. 21 (2014) 51-64. doi:10.1108/ECAM-03-2012-0032.

[7] S. Rafael, C. Eastman, G. Lee, T. Paul, BIM Handbook: A Guide to Building Information Modeling for Owners, Designers, Engineers, Contractors, and Facility Managers, Third Edition, Third, Wiley, Hoboken, New Jersey, 2018.

[8] P. Saieg, E.D. Sotelino, D. Nascimento, R.G.G. Caiado, Interactions of Building Information Modeling, Lean and Sustainability on the Architectural, Engineering and Construction industry: A systematic review, Journal of Cleaner Production. 174 (2018) 788-806.

[9] M. Tauriainen, P. Marttinen, B. Dave, L. Koskela, BIM and Lean Construction Change Design Management Practices, Creative Construction Conference 2016. (2016) 668-673. doi:10.1016/j.proeng.2016.11.659.

[10] Y. Arayici, P. Coates, L. Koskela, M. Kagioglou, C. Usher, K. O'Reilly, Technology adoption in the BIM implementation for lean architectural practice, Automation in Construction. 20 (2011) 189-195. doi:10.1016/j.autcon.2010.09.016.

[11] R. Sacks, L. Koskela, B.A. Dave, R. Owen, Interaction of Lean and Building Information Modeling in Construction, ASCE Journal of Computing in Civil Engineering. 136 (2010) 968-980. doi:10.1061/ASCÊCO.1943-7862.0000203.

[12] O. Hamdi, F. Leite, BIM and Lean interactions from the bim capability maturity model perspective: A case study, IGLC 2012 - 20th Conference of the International Group for Lean Construction. (2012).

[13] J. Clemente, N. Cachadinha, Bim-Lean Synergies in the Management on Mep Works in Public Facilities of Intensive Use - a Case Study, Proceedings IGLC-21. (2013) 751-760.

[14] S. Gao, S.P. Low, Lean construction management: The Toyota way, 2014. doi:10.1007/978-981-287-014-8.

[15] L. Koskela, G. Howell, G. Ballard, I. Tommelein, The foundations of lean construction, in: Design and Construction: Building in Value, 2002: pp. 211-226.

[16] F. Berroir, L. Harbouche, C. Boton, Top Down vs. Bottom Up Approaches Regarding the Implementation of Lean Construction Through a French Case Study, in: Proc. 23rd Annual Conference of the International Group for Lean Construction, Perth, Australia, 2015: pp. 73-82.

[17] G. Ballard, G. Howell, An update on Last Planner, in: Proceedings of the 11th Annual Conference of the International Group for Lean Construction, Virginia, USA, 2004.

[18] H.G. Ballard, The Last Planner, in: Spring Conference of the Northern California Construction Institute, Monterey, CA, 1994.

[19] G. Ballard, G. Howell, Toward construction JIT, in: L.F. Alarcón (Ed.), Lean Construction, Balkema, Rotterdam, 1997: pp. 291-300.

[20] C. Boton, D. Forgues, G. Halin, A framework for Building Information Modeling implementation in engineering education, Canadian Journal of Civil Engineering. 45 (2018). doi:10.1139/cjce-2018-0047.

[21] The Computer Integrated Construction Reseaerch Program, Building Information Modeling Execution Planning Guide, Computer Integrated Construction Research Group, The Pennsylvania State University, 2010.

[22] C. Boton, D. Forgues, Practices and Processes in BIM Projects : An Exploratory Case Study, Advances in Civil Engineering. 2018 (2018) 1-12. doi:https://doi.org/10.1155/2018/7259659.

[23] C. Boton, S. Kubicki, G. Halin, Designing adapted visualization for collaborative 4D applications, Automation in Construction. 36 (2013) 152-167. doi:10.1016/j.autcon.2013.09.003.

[24] M.-A. Vigneault, C. Boton, H.-Y. Chong, B. Cooper-Cooke, An Innovative Framework of 5D BIM Solutions for Construction Cost Management: A Systematic Review, Archives of Computational Methods in Engineering. (2019). doi:10.1007/s11831-019-09341-z.

[25] S. Khan, P. Tzortzopoulos, Effects of the interactions between LPS and BIM on workflow in two building design projects, Proceedings for the 22nd Annual Conference of the International Group for Lean Construction. 1 (2014) 933-944. doi:10.1016/j.autcon.2010.09.013.

[26] O. Seppänen, G. Ballard, S. Pesonen, The Combination of Last Planner System and Location-Based Management System, Lean Construction Journal. (2010) 43-54.

[27] R. Fosse, G. Ballard, M. Fischer, Virtual Design and Construction- Aligning BIM and Lean in Practice, 25th Annual Conference of the International Group for Lean Construction. (2017) 499-506. doi:10.24928/2017/0159.

[28] Y. Arayici, P. Coates, L. Koskela, M. Kagioglou, C. Usher, K. O’Reilly, BIM adoption and implementation for architectural practices, Structural Survey. 29 (2011) 7-25. doi:10.1108/02630801111118377.

[29] A. Guerriero, S. Kubicki, F. Berroir, C. Lemaire, BIM-enhanced collaborative smart technologies for LEAN construction processes, 2017 International Conference on Engineering, Technology and Innovation: Engineering, Technology and Innovation Management Beyond 2020: New Challenges, New Approaches, ICE/ITMC 2017 - Proceedings. 2018-Janua (2018) 1023-1030. doi:10.1109/ICE.2017.8279994.

[30] R. Sacks, R. Barak, B. Belaciano, U. Gurevich, E. Pikas, KanBIM workflow management system: Prototype implementation and field testing, Lean Construction Journal. 2013 (2013) 19-35.

[31] B. Dave, S. Kubler, K. Främling, L. Koskela, Opportunities for enhanced lean construction management using Internet of Things standards, Automation in Construction. 61 (2016) 86-97. doi:10.1016/j.autcon.2015.10.009.

[32] V.J. Bilandzic M., Towards Participatory Action Design Research: Adapting Action Research and Design Science Research Methods for Urban Informatics, The Journal of Community Informatics. 7 (2011). 